\title{
Does size matter?
}

To the Editor, In 1995, I described a modified Cesarean Section (CS), the so-called "Misgav Ladach" method (1) which gained international usage, including both in Turkey (2) and in Germany (3). There are scores of publications from many countries, all showing without exception a notably shorter operative time, and fewer complications of wound healing and reduced hospital stay. Although all display these benefits, the results also demonstrate large statistical variations. These variations are probably due to the lack of standardization of the surgical method, as only studies using a standardized method enable comparison of outcomes among different surgeons and institutions (4).

The opening of the uterus in the classical Misgav Ladach CS, is done by cutting a small transverse incision in the middle of the lower segment and stretching the opening bi-digitally, transversely. In this way, the resulted bleeding is minimal. This enables suturing the uterus in one layer and although controversial, one layer may result in less ruptures during repeated pregnancies (5).

As the uterus contracts immediately after CS, suturing is used mainly for immediate hemostasis. The suture material cannot contract with the uterus therefore; the more suture material left behind the more foreign body reaction, which might result in increased pain, irritation to the bladder and a weaker scar. For many years, I was suturing the uterus with a one-layer continuous locking stitch (6), using an $80 \mathrm{~mm}$ needle, PGA size 1. Using a big needle enables stitching further away from the incision line resulting in excellent hemostasis with minimal steps and less suture material, rarely needing extra single hemostatic sutures.

When using a smaller needle, the surgeon must stitch closer to the incision line, demanding more time and steps, and in case of suturing the uterus in one layer, this could result in the necessity for an additional second layer or single extra stitches for hemostasis.
Standardization of CS is needed in order to be able to compare the outcome among different surgeons and institutions. Comparing outcome of surgeries even performed using the same standardized method but with different sized needles, might lead to different outcome and therefore inaccurate conclusions.

Therefore, it seems that the size of the needle does matter and I highly suggest to routinely using a standardized-sized 80 mm needle.

\author{
Michael Stark ${ }^{1,2}$ \\ ${ }^{1}$ The New European Surgical Academy (NESA), Berlin, Germany \\ ${ }^{2}$ ELSAN Hospital Group, Paris, France
}

\section{References}

1. Stark M, Chavkin Y, Kupfersztain C, Guedj P, Finkel AR. Evaluation of combinations of procedures in cesarean section. Int J Gynaecol Obstet 1995; 48: 273-6. [Crossref]

2. Naki MM, Api O, Celik H, Kars B, Yaşar E, Unal O. Comparative study of Misgav-Ladach and Pfannenstiel-Kerr cesarean techniques: a randomized controlled trial. J Matern Fetal Neonatal Med 2011; 24: 239-44. [Crossref]

3. Heidenreich W, Borgmann U. [Results of the Misgav Ladach caesarean section]. Zentralbl Gynakol 2001; 123: 634-7. [Crossref]

4. Stark M, Gerli S, Di Renzo GC, The importance of analyzing and standardizing surgical methods, in: J Minim Invasive Gynecol 2009; 16: 122-5. [Crossref]

5. Hudić I1, Fatusić Z, Kamerić L, Misić M, Serak I, Latifagić A. Vaginal delivery after Misgav-Ladach cesarean section--is the risk of uterine rupture acceptable? J Matern Fetal Neonatal Med 2010; 23: 1156-9. [Crossref]

6. Holmgren G, Sjöholm L, Stark M. The Misgav Ladach method for cesarean section: method description. Acta Obstet Gynecol Scand 1999; 78: 615-21. [Crossref] 